\title{
Research
}

\section{Nursery sickness policies and their influence on prescribing for conjunctivitis:}

\author{
audit and questionnaire survey
}

\begin{abstract}
Background

Acute infective conjunctivitis is common among preschool children. Public Health England (PHE) recommends that children with conjunctivitis do not need to be excluded from child care, but childcare providers are required to determine their own sickness policies and prior research suggests that children are often excluded until they are treated or have recovered. How the content of these policies impacts on prescribing decisions has not been quantified.
\end{abstract}

\section{Aim}

To assess the content of childcare providers sickness policies and determine the impact they have on clinicians' prescribing.

\section{Design and setting}

An audit of childcare providers' sickness policies and a questionnaire among primary care clinicians.

\section{Method}

Sickness policies from childcare providers across the UK were compared with PHE guidance. Clinicians completed a questionnaire on the impact that childcare provider policies have on their decision to prescribe antibiotics to preschool children with conjunctivitis.

\section{Results}

Of 164 policies examined, $86.7 \%$ excluded children with conjunctivitis and $49.4 \%$ of policies specified a requirement for antibiotics. Two-hundred clinicians completed questionnaires and $42.6 \%$ replied that they had been influenced by childcare policies when deciding whether to prescribe antibiotics in this scenario. Furthermore, 15.4\% admitted that childcare policies had been the only reason they prescribed antibiotics.

\section{Conclusion}

Most of the childcare providers' sickness policies contain requirements that are inconsistent with PHE guidance. The requirements of childcare sickness policies are likely to be resulting in unnecessary primary care consultations and thousands of prescriptions for antibiotics with little demonstrable clinical or public health benefit.

\section{Keywords}

antibiotics; child care; conjunctivitis; primary health care.

\section{INTRODUCTION}

Acute infective conjunctivitis (AIC) is a common condition in preschool children. It is usually mild and self-limiting, often with no requirement for treatment or a doctor's appointment. ${ }^{2}$ Evidence suggests, however, that parents and guardians are advised by childcare providers (CPs) to take their children with conjunctivitis to their GP for assessment. ${ }^{3-5}$ Furthermore, some CPs will not permit affected children to return to child care until antibiotics have been prescribed, ${ }^{3,4,6,7}$ thus parents are obtaining antibiotics to get their child readmitted. A situation in which antibiotics are prescribed for non-clinical reasons is difficult to justify and requires further investigation.

Although most cases (50-75\%) of AIC are bacterial in origin, ${ }^{8}$ the aetiology is difficult to determine clinically and only $36 \%$ of doctors are confident in differentiating between viral and bacterial conjunctivitis. ${ }^{9,10}$ In bacterial conjunctivitis, there may be some clinical benefit obtained from topical antibiotics: ${ }^{11}$ however, this benefit is perhaps not seen in children and topical chloramphenicol shortens the duration of symptoms by only 0.3 days. ${ }^{2}$ Despite this, most clinicians usually prescribe antibiotics for AIC. ${ }^{10}$

Perceived pressure from parents, employers, educators, and pharmaceutical companies are factors that influence the decision to prescribe antibiotics to children with acute infections. ${ }^{12}$ For AIC, GPs report that the need for the child to return to nursery can be paramount in the decision to prescribe antibiotics. ${ }^{3}$ Parental pressure may originate from an unrealistic view of the benefit of antibiotics as $60.8 \%$ of parents believe their child will not get better without treatment. ${ }^{3}$ Parents may also be the means through which pressure from CPs is exerted, although the evidence regarding this is conflicting. One study reported that $\mathrm{CP}$ attendance was not seen as a significant influence in parents seeking treatment, ${ }^{13}$ whereas another indicated that some parents seek antibiotics solely for the purposes of preventing exclusion or expediting readmission. ${ }^{4}$

Childcare providers in the UK follow a statutory framework which stipulates that they must have a procedure for responding to children who are ill or infectious, but gives no details about what this should be. ${ }^{14}$ Public Health England (PHE) land equivalent organisations internationallyl advise on managing infectious diseases to reduce the public health burden. The PHE guidance states that no school or nursery exclusion is required for children with $\mathrm{AIC}$, and there is no requirement for treatment with antibiotics. ${ }^{15}$ This message is echoed in Welsh and Scottish guidance, as well as the equivalent US document, which states that there is no evidence that treatment or exclusion reduces the spread of conjunctivitis. ${ }^{16-18}$

There is evidence that sickness policies of CPs do not always comply with public health advice. An audit of policies from $58 \mathrm{CPs}$ in Wales found that $95 \%$ required
S Finnikin, MSc, MRCGP, research fellow, Primary Care Clinical Sciences; K Jolly, MSc, PhD, MFPH, professor of public health and primary care, Health and Population Sciences, Public Health, Epidemiology and Biostatistics, University of Birmingham, Birmingham.

\section{Address for correspondence}

Samuel Finnikin, Primary Care Clinical Sciences, Institute of Applied Health Research, College of Medical and Dental Sciences, University of
Birmingham, Edgbaston, Birmingham B15 2TT, UK E-mail: Finniksjabham.ac.uk

Submitted: 6 January 2016; Editor's response: 25 February 2016; final acceptance: 16 March 2016. CBritish Journal of General Practice

This is the full-length article (published online 6 Jul 2016) of an abridged version published in print. Cite this version as: $\mathbf{B r} \mathbf{J}$ Gen Pract 2016; DOI: 10.3399/bjgp16X686125 


\section{How this fits in}

Other studies have shown that childcare sickness exclusion policies do not always follow public health guidance. Using acute infective conjunctivitis as an exemplar, the present study confirms this disparity and establishes that these policies are likely to be leading to unnecessary consultations and prescriptions for antibiotics in primary care. Finding solutions to this problem would be a step towards more rational antibiotic prescribing in primary care. GPs are ideally positioned to help local childcare providers produce evidence-based policies but dealing with the issue at a national level is surely the most effective solution.

children with AIC to be excluded. ${ }^{4} \mathrm{~A}$ similar result was found among English nurseries in 2005..$^{3}$ Excluded children are likely to be taken to their GP lindeed this may be required by their $\mathrm{CP}$ ) resulting in potentially unnecessary consultations. In the US, $88 \%$ of parents sought acute medical care for children who had been excluded from a childcare setting. ${ }^{19}$

This study aimed to establish what proportion of sickness policies of UK CPS comply with PHE guidance, and examining how these policies influence prescribing of antibiotics to preschool children with AIC.

\section{METHOD}

Data were collected from two sources: an analysis of daycare nursery sickness policies and a questionnaire among primary care prescribers.

\section{Content of childcare providers' policies}

A search was performed in January 2015 using the terms 'nursery' AND 'conjunctivitis' in Google ${ }^{\mathrm{TM}}$ limited to UK domains and the dates 1 April 2010 to 31 December 2014 to exclude policies published before the latest PHE guidance. All returned page descriptions were examined but only those pertaining to nursery sickness policies were included in the data collection.
Data were extracted to IBM SPSS Statistics (version 21). Exclusion criteria were coded according to predetermined categories that had arisen through scoping searches. Where two or more criteria were specified, the most restrictive was recorded. Any advice relating to antibiotics was recorded as well as whether a source of information was quoted and whether the nursery belonged to a larger group of nurseries or not. The postcode of the nursery and an e-mail contact were also obtained.

Analysis was performed in SPSS and was primarily descriptive. Confidence intervals (Cls) on single proportions were calculated ${ }^{20}$ and $\chi^{2}$ or Fisher exact tests were used to test the relationship between categorical variables.

\section{Questionnaire to prescribers}

A questionnaire was designed to quantify the extent to which primary care clinicians feel they are influenced by CPs' policies when deciding whether to prescribe antibiotics to preschool children with AIC. The population of interest consisted of prescribing primary care clinicians (GPs, GP registrars, and nurse prescribers). A pragmatic approach to sampling was required and this resulted in a chunk sampling method. ${ }^{21}$ Clinicians who attended three educational events in the West Midlands were invited to participate and questionnaires were distributed at registration and collected at the end of the event. The topics of the events were broadly clinical but none focused on antimicrobial stewardship or conjunctivitis.

Demographic and occupational characteristics of the participants were obtained. Participants not able to prescribe chloramphenicol to preschool children were excluded. Participants were asked to consider a vignette of a preschool child diagnosed with $\mathrm{AIC}$ and respond to three statements about the influence of $\mathrm{CP}$ policies on their prescribing decisions (Box 1). An open 'any comments' question was included to illustrate important points, identify points of contention or conflict, and potentially identify avenues for further

\section{Box 1. Questionnaire vignette and question stems}

For the following questions, please consider the scenario of a preschool child who presents with their parent or guardian. You have made a diagnosis of acute infective conjunctivitis.

1. Have you ever prescribed topical antibiotics (for example, chloramphenicol eye drops) in this situation?

2. Has the policy of a childcare provider (for example, daycare nursery) ever influenced your decision to prescribe in this situation?

3. Has the policy of a childcare provider ever been the main reason you have prescribed in this situation?

4. Has the policy of a childcare provider ever been the only reason you have prescribed in this situation? 


\section{Box 2. Illustrative extracts from sickness policies}

... child will be sent home and can return when medication has been prescribed.

'Children with conjunctivitis may attend, but exclusion may become necessary if there is an outbreak and the situation becomes unmanageable, as per the Health Protection Agency's advice.

'Exclusion not always necessary, however a doctor's opinion must be sought.'

'Conjunctivitis is extremely infectious and children should not attend nursery until symptom free.

We will also not administer antibiotics for conjunctivitis. In cases of this, children should return to nursery when the conjunctivitis has cleared. I.e. the infection is no longer weeping out the eye sockets.'

investigation through content analysis. ${ }^{22}$ Statistical analysis was performed as above. Binary logistic regression was undertaken to identify any clinician characteristics that increased the likelihood of being influenced by CP policies.

\section{RESULTS}

The internet search returned 273 unique pages, of which 164 (60.1\%) were relevant CP sickness policies. Fourteen per cent of CPs were group nurseries; the rest were individual organisations. The nurseries were spread across England, Scotland, and Wales, with some clustering around large urban areas.

Only 22 policies $113.4 \% ; 95 \% \mathrm{Cl}=9.0 \%$ to $19.5 \%$ ) stated that no exclusion was required for children with AIC l'compliant' $\mathrm{CPs})$. The remaining $\mathrm{CP}$ policies required exclusion ('non-compliant' CPs). There was considerable heterogeneity in the requirements specified for an excluded child to be allowed to return (Box 2) and these were grouped into the predefined categories (Table 1). Twenty-two CPs (13.4\%) had more than one exclusion criterion (most commonly ' $X$ days of antibiotics' and 'until symptom free').

Overall, almost half 181, 49.4\%: $95 \% \mathrm{Cl}=41.8 \%$ to $57.0 \%$ ) of the policies

\section{Table 1. Childcare provider policies exclusion criteria}

\begin{tabular}{lc} 
Exclusion criteria & $\begin{array}{c}\text { Occurrence } \\
\text { (\%) }\end{array}$ \\
\hline Until symptom free & $60(36.6)$ \\
$X$ days of antibiotics completed & $28(17.1)$ \\
None & $22(13.4)$ \\
Until prescribed antibiotics & $22(13.4)$ \\
After X days of treatment or symptom free & $17(10.4)$ \\
Until GP seen & $9(5.5)$ \\
Specified number of days & $6(3.7)$ \\
\hline
\end{tabular}

required treatment with antibiotics before a child with AIC was readmitted to nursery (Table 2). Some policies quoted a source; 23 CPs (14.0\%; $95 \% \mathrm{Cl}=9.5 \%$ to $20.2 \%$ ) quoted PHE (or the Health Protection Agency), but, of these, only nine $140.9 \% ; 95 \% \mathrm{Cl}=23.3 \%$ to $61.3 \%$ ) had an exclusion policy in line with PHE guidance. Those CPs that quoted PHE were significantly more likely to follow PHE guidance than nurseries that did not quote a source $(P<0.001)$ (Table 3). Group nurseries were not significantly more likely to follow PHE guidance than individual organisations (21.7\% versus $12.0 \%, P=0.20$ ).

\section{Questionnaire to clinicians}

Of the 428 questionnaires distributed, 200 (46.7\%) were returned completed. Table 4 shows the characteristics of the responders.

Overall, $42.6 \%$ (95\% $\mathrm{Cl}=35.7 \%$ to $49.7 \%$; $n=80$ ) of eligible responders reported that their prescribing of topical antibiotics in AIC has been influenced by CP policies. One-quarter $(25.5 \% ; 95 \% \mathrm{Cl}=19.8 \%$ to $32.2 \% ; n=48)$ stated that CP policy was the main reason they had prescribed, and in $15.4 \%(95 \% \mathrm{Cl}=11.0 \%$ to $21.3 \% ; n=29)$ of responses this was the only reason for prescribing.

Only the age of the clinician showed a significant association with a positive response to the 'ever influenced' stem. Both age categories 30-39 years (OR $2.25 ; 95 \% \mathrm{Cl}=1.04$ to $4.87, P=0.04)$ and 40-49 years (OR 2.25; $95 \% \mathrm{Cl}=1.14$ to 4.45 , $P=0.02$ ) were significantly more likely to have been influenced by $\mathrm{CP}$ policies than the $\geq 50$ years age category. This association was not present for the 'main reason' and 'only reason' stems.

Forty-seven participants elected to leave comments on the questionnaire. Some of these comments demonstrated an awareness of the situation and the difficulty it presented to prescribers and parents:

I have found it very frustrating feeling compelled to prescribe because working mothers tell me the child cannot attend nursery until they have been treated.'

Other responses suggested a more clinically dogmatic approach to prescribing:

Antibiotics are given when needed. Childcare provider pressure does not work.

Finally, some participants noted that they have tried to develop solutions to the problem:

I print off a copy of the HPA guidance ... and 
Table 2. Antibiotics references in childcare provider policies

\begin{tabular}{lc} 
Stated requirement for antibiotics & Occurrence \\
\hline Not mentioned & (\%) \\
\hline Must be started before return & $25(48.2)$ \\
Must have completed X days of antibiotics & $56(34.1)$ \\
Not required & $4(2.4)$ \\
\hline
\end{tabular}

Table 3. Relationship between source referenced and compliance of policies with PHE guidance

\begin{tabular}{lccc} 
Source & $\begin{array}{c}\text { Number } \\
\text { of policies }\end{array}$ & $\begin{array}{c}\text { Number } \\
\text { compliant (\%) }\end{array}$ & P-value $^{\mathbf{a}}$ \\
\hline None & 128 & $10(7.8)$ & \\
Public Health England & 22 & $9(39.1)$ & $<0.001^{\text {b }}$ \\
Other & 14 & $3(21.4)$ & $0.12^{c}$ \\
\hline aversus policies with no source quoted ${ }^{b} x^{2}$ test cFisher
\end{tabular}

aversus policies with no source quoted. ${ }^{b} \chi^{2}$ test. ${ }^{c}$ Fisher exact test. nursery policies rather than clinical need.

The CP policies suggest that many children are being sent to their GP to be prescribed antibiotics for AIC, yet only $43 \%$ of clinicians admit to being influenced by $\mathrm{CP}$ policies in this clinical scenario. Therefore, this figure may be higher. The estimate may be inaccurate because parents are purchasing antibiotics directly from pharmacies lavailable for children aged $\geq 2$ years), supported by evidence of increased over-the-counter sales of chloramphenicol. ${ }^{24}$ Alternatively, perhaps the study findings underreport the true influence of CP policies because of bias. There is inherent sampling and responder bias in the questionnaire methodology, but there is also potential for what may be termed 'professional acceptability bias' lanalogous to social acceptability bias). ${ }^{25}$ Here, responses may be prejudiced by what the participant feels someone in their profession should be doing, rather than reporting what they are actually doing if it may be considered unprofessional. Despite these potential biases, the fact that 15\% of clinicians report prescribing antibiotics because of CP policies is a significant finding given the lack of evidence underpinning exclusion practices.

\section{Summary}

From the CP policies examined, clearly there is a large disparity between the sickness exclusion practices of nurseries and the advice issued by public health authorities. Most nurseries excluded children with AIC but there was a huge amount of heterogeneity in the constraints imposed before children could return to nursery. Many policies required children to be symptom free before returning, which, although potentially justifiable given that AIC can easily be transmitted, could result in several days away from nursery for a child who may be quite well. This obviously has economic and social ramifications for the child's main caregivers.

Perhaps more significantly, nearly half of all policies necessitated antibiotics to be prescribed to the child before readmission to nursery. Although antibiotics may marginally reduce clinical recovery time, to allow a child to return to nursery because they have commenced antibiotics (as one-third of policies state) makes no sense clinically as there is no evidence that treatment decreases transmission of AIC. With 1.2 million children in nurseries ${ }^{23}$ and $20 \%$ of preschool children presenting to their GP with conjunctivitis each year, ${ }^{1}$ there are potentially 240000 consultations, 120000 antibiotic prescriptions, and 360000 days lost from work ${ }^{3}$ that are a result of
This examination of CP sickness policies is the most comprehensive to date in terms of the number and variety of CPs included and is the first study to demonstrate audit of $\mathrm{CP}$ policies using publicly available information. It is a simple methodology that provides a snapshot of current practice. By obtaining data from policies published on the internet, responder bias was eliminated. Rose and colleagues ${ }^{3}$ and Rooshenas and colleagues ${ }^{4}$ had response rates of $74.0 \%$ and $55.0 \%$, respectively. Reliability of the results is further improved through direct analysis of the policy rather than, as Rose and colleagues did, relying on CPs to answer questions on the content of their policies.

Not all CPs have websites, but there is no reason to suggest that the sickness policies of CPs with an online presence should be systematically different from those without. Indeed, it is probable that CPs that publish their sickness policies online are more likely to believe that their policy is evidence-based than those that do not. Thus any bias from the sampling is likely to be in the direction of under-identification of non-compliant policies. Despite including all the policies available, however, this represented only a

\section{Strengths and limitations} small fraction of the approximately 25000 
UK-registered nurseries. ${ }^{23}$ Additionally, the policies of CPs other than nurseries have the potential to exert similar influence on clinicians, but these were not investigated.

The questionnaire to clinicians was designed to measure the influence that CPs have on prescribing but was not validated. This is the first time this has been explored in a quantitative way. It is difficult, however, to quantify something as intangible as 'influence' and a questionnaire method can only provide an approximate measure. Furthermore, the sample was limited to clinicians working in one geographical area of the UK and, although the analysis of CPs' policies above does not suggest any systematic geographical variation, this may affect generalisability of the findings. Additionally, the sample was drawn from attendees at educational events, which introduced a sampling bias. A response rate of $46.7 \%$ may compound the impact of responder bias as it is slightly lower than expectations informed by the literature. ${ }^{26,27}$

This research has not considered the views of parents or CPs on this subject, although some work has previously been undertaken in this area. ${ }^{4,28}$ Further research with CPs is necessary to gain a better understanding of the rationale behind the content of sickness policies.

\section{Comparison with existing literature}

The degree of dissidence of CP policies with public health guidance is consistent with that found in previous studies adding reliability to the finding. ${ }^{3,4}$ Rooshenas and colleagues also considered whether CPs required children with $\mathrm{AIC}$ to receive treatment. ${ }^{4}$ Of the 58 policies they identified that mentioned conjunctivitis, 18 specified a requirement for treatment $(31.0 \% ; 95 \% \mathrm{Cl}=20.6 \%$ to $43.8 \%$ [Cl calculated from original data]], which is comparable with the results of the present study. Sickness policies in the US require antibiotics to be given for AIC in most cases.?

Qualitative studies have found that clinicians often feel pressure to prescribe because of the policies of $\mathrm{CPs}_{1}, 29,30$ but this study is the first attempt to quantify the impact of this pressure.

\section{Implications for practice}

Many GPs will be aware of this issue already but this research highlights the potential impact of clinically unjustifiable sickness exclusion practices. Even though antibiotics are rarely clinically indicated for AIC, it is easy to see why clinicians may feel that a prescription is required.

To reduce inappropriate prescribing, one strategy would be to improve CPs' understanding of AIC and encourage them to adhere to public health guidance. Further research may inform strategies to achieve this. GPs are perhaps best positioned to lead improvement by building relationships between themselves and local CPs. Although this would require an initial resource investment, this may be offset by a reduction in inappropriate consultations.

To make significant changes, CP policies should be influenced at a national level. Adherence to guidance could be improved through existing Ofsted inspections examining the policy content. CPs not following PHE guidance could be required to explain this decision to ensure that disparities are justifiable.

\section{Provenance}

Freely submitted; externally peer reviewed.

\section{Competing interests}

The authors have declared no competing interests.

\section{Acknowledgements}

We would like to thank all of the clinicians who took the time to fill in questionnaires and provide us with their views and the organisations that allowed us to hand out questionnaires during their events: Sandwell and West Birmingham CCG, RCGP West Midland Faculty, and Health Education West Midlands. Additional thanks go to the academic clinical fellows from the Department of Primary Care at the University of Birmingham for questionnaire design feedback.

\section{Discuss this article}

Contribute and read comments about this article: bjgp.org/letters 


\section{REFERENCES}

1. McCormick M, Fleming D, Charlton J. Morbidity statistics from general practice: fourth national survey 1991-1992. London: HMSO; 1995

2. Rose PW, Harnden A, Brueggemann AB, et al. Chloramphenicol treatment for acute infective conjunctivitis in children in primary care: a randomised doubleblind placebo-controlled trial. Lancet 2005; 366(9479): 37-43.

3. Rose PW, Ziebland S, Harnden A, et al. Why do general practitioners prescribe antibiotics for acute infective conjunctivitis in children? Qualitative interviews with GPs and a questionnaire survey of parents and teachers. Fam Pract 2006 23(2): 226-232

4. Rooshenas L, Wood F, Brookes-Howell L, et al. The influence of children's day care on antibiotic seeking: a mixed methods study. Br J Gen Pract 2014; DOI: 10.3399/bjgp14X679741.

5. Kahan E, Gross S, Cohen HA. Exclusion of ill children from child-care centers in Israel. Patient Educ Couns 2005; 56(1): 93-97.

6. Hashikawa AN, Stevens MW, Juhn YJ, et al. Self-report of child care directors regarding return-to-care. Pediatrics 2012; 130(6): 1046-1052.

7. M'ikanatha NM, Gasink LB, Kunselman A, et al. Child care center exclusion policies and directors' opinions on the use of antibiotics. Infect Control Hosp Epidemiol 2010; 31(4): 408-411.

8. Høvding G. Acute bacterial conjunctivitis. Acta Ophthalmol 2008; 86(1): 5-17.

9. Rietveld RP, ter Riet G, Bindels PJ, et al. Predicting bacterial cause in infectious conjunctivitis: cohort study on informativeness of combinations of signs and symptoms. BMJ 2004; 329(7459): 206-210.

10. Everitt H, Little P. How do GPs diagnose and manage acute infective conjunctivitis? A GP survey. Fam Pract 2002; 19(6): 658-660.

11. Sheikh A, Hurwitz B, van Schayck CP, et al. Antibiotics versus placebo for acute bacterial conjunctivitis. Cochrane Database Syst Rev 2012; (9): CD001211.

12. Lucas PJ, Cabral C, Hay AD, Horwood J. A systematic review of parent and clinician views and perceptions that influence prescribing decisions in relation to acute childhood infections in primary care. Scand J Prim Health Care 2015; 33(1): 11-20.

13. Everitt $H$, Kumar S, Little P. A qualitative study of patients' perceptions of acute infective conjunctivitis. Br J Gen Pract 2003; 53(486): 36-41.

14. Department for Education. Statutory framework for the early years foundation stage. Setting the standards for learning, development and care for children from birth to five. 2014. https://www.gov.uk/government/uploads/ system/uploads/attachment data/file/335504/EYFS framework from 1 September 2014 with clarification note.pdf (accessed 15 Jun 2016).

15. Public Health England. Guidance on infection control in schools and other childcare settings. 2016. https://www.gov.uk/government/uploads/system/ uploads/attachment_data/file/353953/Guidance_on_infection_control_in schools_11_Sept.pdf (accessed 15 Jun 2016).

16. American Academy of Pediatrics, American Public Health Association, National
Resource Center for Health and Safety in Child Care and Early Education. Caring for our children: national health and safety performance standards: Guidelines for early care and education programs. 3rd edn. 2011. http:// www.healthybeveragesinchildcare.org/resources/CaringForOurChildren_ NationalHealthandSafetyStandards.2011.pdf (accessed 15 Jun 2016).

17. Health Protection Scotland. Infection prevention and control in childcare settings (day care and childminding settings). 2015. http://www.documents. hps.scot.nhs.uk/hai/infection-control/guidelines/infection-prevention-controlchildcare-2015-v2.pdf (accessed 15 Jun 2016).

18. Public Health Wales. Infection prevention and control for childcare settings 10-5 years/. 2014. http://mww.wales.nhs.uk/sitesplus/documents/888/Infection \%20 Prevention\%20and\%20Control\%20for\%20Childcare\%20Settings\%20Final\%20 2014.pdf (accessed 15 Jun 2016).

19. Hashikawa AN, Brousseau DC, Singer DC, et al. Emergency department and urgent care for children excluded from child care. Pediatrics 2014; 134(1): e120-e127.

20. Altman D, Machin D, Bryant T, Gardner M. Statistics with confidence. 2nd edn London: BMJ Publications, 2000

21. Burns KE, Duffett $M$, Kho ME, et al. A guide for the design and conduct of selfadministered surveys of clinicians. CMAJ 2008; 179(3): 245-252.

22. O'Cathain A, Thomas KJ. Any other comments? open questions on questionnaires - a bane or a bonus to research. BMC Med Res Methodol 2004 4: 25

23. Ofsted. The report of Her Majesty's Chief Inspector of Education, Children's Services and Skills: early years annual report 2012/13. 2014. https://uww.gov. uk/government/uploads/system/uploads/attachment data/file/386504/Ofsted Early_Years_Annual_Report_201213.pdf. (accessed 15 Jun 2016).

24. Davis H, Mant D, Scott C, et al. Relative impact of clinical evidence and over-the-counter prescribing on topical antibiotic use for acute infective conjunctivitis. Br J Gen Pract 2009; DOI: 10.3399/bjgp09X473132

25. Stewart A. Basic statistics and epidemiology: a practical guide. Abingdon: Radcliffe Publishing, 2010.

26. Kellerman SE, Herold J. Physician response to surveys: a review of the literature. Am J Prev Med 2001; 20(1): 61-67.

27. Sibbald B, Addington-Hall J, Brenneman D, Freeling P. Telephone versus postal surveys of general practitioners: methodological considerations. Br J Gen Pract 1994; 44(384): 297-300.

28. Carroll FE, Rooshenas L, Owen-Smith A, et al. Factors influencing parents' decision-making when sending children with respiratory tract infections to nursery. J Public Health (Oxf) 2015; Apr 22. pii: fdv037. [Epub ahead of print].

29. Kahan E, Gross S, Horev Z, et al. Pediatrician attitudes to exclusion of ill children from child-care centers in Israel: pressure on ambulatory practices. Patient Educ Couns 2006; 60(2): 164-170

30. Barden LS, Dowell SF, Schwartz B, Lackey C. Current attitudes regarding use of antimicrobial agents: results from physician's and parents' focus group discussions. Clin Pediatr (Phila) 1998; 37(11): 665-671. 